\title{
Effect of chlorophyll biosynthesis-related genes on the leaf color in Hosta (Hosta plantaginea Aschers) and tobacco (Nicotiana tabacum L.)
}

Jingying Zhang ${ }^{1}$, Changhai Sui ${ }^{1,2}$, Huimin Liu', Jinjiao Chen ${ }^{1}$, Zhilin Han ${ }^{1}$, Qian Yan ${ }^{1}$, Shuying Liu ${ }^{1 *}$ and Hongzhang Liü ${ }^{*}$

\begin{abstract}
Background: 'Regal Splendour' (Hosta variety) is famous for its multi-color leaves, which are useful resources for exploring chloroplast development and color changes. The expressions of chlorophyll biosynthesis-related genes ( HrHEMA, HrPOR and HrCAO) in Hosta have been demonstrated to be associated with leaf color. Herein, we isolated, sequenced, and analyzed HrHEMA, HrPOR and HrCAO genes. Subcellular localization was also performed to determine the location of the corresponding enzymes. After plasmid construction, virus-induced gene silencing (VIGS) was carried out to reduce the expressions of those genes. In addition, HrHEMA-, HrPOR- and HrCAOoverexpressing tobacco plants were made to verify the genes function. Changes of transgenic tobacco were recorded under $2000 \mathrm{x}, 6000 \mathrm{~lx}$ and 10,000 lx light intensity. Additionally, the contents of enzyme 5-aminolevulinic acid (5-ALA), porphobilinogen (PBG), chlorophyll $a$ and b (Chla and Chlb), carotenoid (CXc), superoxide dismutase (SOD), peroxidase (POD), malondialdehyde (MDA), proline (Pro) and catalase (CAT) under different light intensities were evaluated.

Results: The silencing of HrHEMA, HrPOR and HrCAO genes can induce leaf yellowing and chloroplast structure changes in Hosta. Specifically, leaves of Hosta with HrCAO silencing were the most affected, while those with HrPOR silencing were the least affected. Moreover, all three genes in tobacco were highly expressed, whereas no expression was detected in wild-type (WT). However, the sensitivities of the three genes to different light intensities were different. The highest expression level of HrHEMA and HrPOR was detected under 10,000 Ix of illumination, while HrCAO showed the highest expression level under $6000 \mathrm{~lx}$. Lastly, the 5-ALA, Chla, Cxc, SOD, POD, MDA, Pro and CAT contents in different transgenic tobaccos changed significantly under different light intensities.

(Continued on next page)
\end{abstract}

\footnotetext{
* Correspondence: liushuyingbr@ilau.edu.cn; jlaulhz@163.com

${ }^{1}$ College of Life sciences, Jilin Agricultural University, 2888 Xincheng Street, Changchun City 130000, People's Republic of China

Full list of author information is available at the end of the article
}

(c) The Author(s). 2021 Open Access This article is licensed under a Creative Commons Attribution 4.0 International License, which permits use, sharing, adaptation, distribution and reproduction in any medium or format, as long as you give appropriate credit to the original author(s) and the source, provide a link to the Creative Commons licence, and indicate if changes were made. The images or other third party material in this article are included in the article's Creative Commons licence, unless indicated otherwise in a credit line to the material. If material is not included in the article's Creative Commons licence and your intended use is not permitted by statutory regulation or exceeds the permitted use, you will need to obtain permission directly from the copyright holder. To view a copy of this licence, visit http://creativecommons.org/licenses/by/4.0/ The Creative Commons Public Domain Dedication waiver (http://creativecommons.org/publicdomain/zero/1.0/) applies to the data made available in this article, unless otherwise stated in a credit line to the data. 
(Continued from previous page)

Conclusion: The overexpression of these three genes in tobacco enhanced photosynthesis by accumulating chlorophyll content, but the influential level varied under different light intensities. Furthermore, HrHEMA-, HrPORand $\mathrm{HrCAO}$ - overexpressing in tobacco can enhance the antioxidant capacity of plants to cope with stress under higher light intensity. However, under lower light intensity, the antioxidant capacity was declined in HrHEMA-, HrPOR- and HrCAO- overexpressing tobaccos.

Keywords: HrHEMA, HrPOR, HrCAO, Chlorophyll, Transgenosis, Hosta, Tobacco

\section{Highlights}

1. Silencing $\operatorname{HrHEMA}, \mathrm{HrPOR}$ and $\mathrm{HrCAO}$ changed the cell permeability and resulted in accumulation of autophagic in vesicles.

2. Overexpressing of $\operatorname{HrHEMA,HrPOR}$ and $\mathrm{HrCAO}$ in tobacco enhanced photosynthesis by accumulating chlorophyll content, but the influential level deferred under different light intensity.

3. $\mathrm{HrCAO}$ overexpressing promoted flowering in tobacco plants.

4. Overexpressing of $\mathrm{HrHEMA}, \mathrm{HrPOR}$ and $\mathrm{HrCAO}$ in tobacco can enhance the antioxidant capacity of plants to cope with stress under higher light intensity.

\section{Background}

Hosta (Hosta plantaginea Aschers) is a perennial herbaceous and shade-loving plant of the family Liliaceae [1]. Its leaves vary in shape, size, color and texture. Furthermore, the cost of cultivation and maintenance of Hosta is relatively low, all of which will make it be widely used in urban greening and landscape construction [2]. Despite the ornamental value, Hosta plants also have important medicinal properties including heat-clearing and detoxifying functions. For instance, Liu noted that steroidal saponins extracted from the flower of Hosta exhibited anti-tumor effects [3]. Notably, the 'Regal Splendour', a Hosta variety, is famous for its multi-color leaves. The variegated leaves usually consist of green and white/yellow sectors, which are useful resources for studying chloroplast development and color changes [4]. Moreover, variegated leaf cells of variegated plants enumerated different characteristics with green eaves such as the chloroplast ultrastructure [5-7], construction and function of photosystem I (PSI) and photosystem II (PSII) [8, 9], and chlorophyll synthesis and degradation [5], which may mediate leaf color changing. Also, albinism plays a significant role in the changes in leaf color $[10,11]$. Studies have reported that the expression alteration of each gene related to chloroplast may affect the biogenesis of chloroplasts. The resultant disruption in chlorophyll metabolism and chloroplast assembly can lead to abnormal leaf color [12, 13]. In chlorophyll biosynthesis, the HEMA gene encodes glutamyl-tRNA reductase (GluTR), which is one of the key regulators for encoding enzyme 5-aminolevulinic acid (5-ALA). The enzyme 5-ALA is synthesized from glutamate through three enzymatic reactions. Firstly, glutamate is converted to glutamyl adenylate and then transferred to specific tRNA to form glutamyl-tRNA. Thereafter, the GluTR catalyzes glutamyl-tRNA. to Glu 1-semialdehyde (GSA) in an NADPH-dependent reaction, and thus 5ALA is formed by GSA aminotransferase [14]. Elsewhere, Kumar found that HEMA1 loss-of-function mutants presented patchy to completely yellow color and failed to thrive under normal growth conditions [15]. Another study by Schmied et al. elucidated that HEMA1 overexpression in etiolated and dark-grown plants can lead to protochlorophyllide accumulation [16]. Subsequently, the reduction of protochlorophyllide (Pchlide) to chlorophyllide, catalyzed by the enzyme protochlorophyllide oxidoreductase (POR), is the key light-driven reaction that lead to a profound transformation in plant development [17-20]. As the first step of lightdependent process in chloroplast biosynthesis, the expression of $P O R$ is related to the content of chlorophyll. In angiosperms, two POR isoforms (PORA and PORB) were first identified in Hordeum vulgare [21], Arabidopsis (Arabidopsis thaliana) [22], and some other plant species. Additionally, PORA transcripts up-regulated in young etiolated seedlings and down-regulated by light; whereas PORB transcripts were detected in dark-grown seedlings, as well as still remain detectable at later stages of development in the light [23]. The ternary complex formed by Chla, NADPH and POR is critical to the transformation from white body to chloroplast. Several studies has demonstrated that under the action of Chl synthase, Chla is eventually formed $[24,25]$. In addition, Chlb is synthesized from Chla in a two-step oxygenation reaction catalayzed by Chla oxygenase (CAO) [26]. HEMA, POR and CAO all play a vital role in the process of chlorophyll synthesis and are closely related to leaf color. Their expression level may be involved in the regulation of plant leaf color. Herein, we sought to explore the functions of $\mathrm{HrHEMA}, \mathrm{HrPOR}$ and $\mathrm{HrCAO}$ through gene silencing and overexpressing techniques in Hosta and tobacco plants. Lastly, the sensitivity of 
transgenic plants to light was studied under different light intensities. This study provides new evidences for the variegated leaves in Hosta.

\section{Results}

Identification of HrHEMA, HrPOR and HrCAO

The full-length of $\mathrm{HrHEMA}, \mathrm{HrPOR}$ and $\mathrm{HrCAO}$ was 1608, 1185 and 1623 bp (Table S1), which encoded 536, 394 and 540 amino acids, respectively. Notably, sanger sequence results of the three genes are identical to those of the reference from NCBI (Fig. S1, S2 and S3). Besides, the maximum likelihood (ML) trees were constructed based on the Sanger results and sequences obtained in NCBI using MEGA 7.0 (Fig. 1a-c). The phylogenetic trees revealed that all HrHEMA and $\mathrm{HrCAO}$ protein queries were clustered into four and three groups, respectively. Hosta was clustered together with Asparagus officinalis (Liliaceae), indicating that genes HEMA and CAO in Hosta and A. officinalis were more similar than those in other plants. For $\operatorname{HrPRO}$, the protein queries were clustered into four groups, while no other plants were clustered with Hosta. Collectively, the relationship enumerated that the results of the phylogenetic tree were consistent with those obtained using the the Angiosperm Phylogeny Group (APG) IV system.

\section{Subcellular localization}

In order to identify the subcellular localization of the HrHEMA, HrPOR and HrCAO proteins, the full-length coding sequence (CDS) of the HrHEMA, HrPOR and $H r C A O$ genes was cloned into an expression vector containing the GFP tag (16,318 h-GFP, 35S:GFP), separately. The 16,318 h-HrHEMA-GFP, $16318 \mathrm{~h}-H r P O R-G F P$ and $16,318 \mathrm{~h}-\mathrm{HrCAO}-\mathrm{GFP}$ fusion proteins were mainly distributed in chloroplast (higher brightness) (Fig. 2a-c). While GFP expressed from the empty expression vector (16,318 h-GFP, 35S:GFP), which served as a control, was mainly distributed in both chloroplast and nucleus (Fig. $2 \mathrm{~d})$. The distribution of the fusion proteins indicated that all the three proteins mainly located in the chloroplasts. This result was consistent with that predicted by bioinformatics.

\section{Effect of silenced HrHEMA, HrPOR and HrCAO on Hosta plantaginea}

Silencing of HrHEMA, HrPOR and HrCAO genes in Hosta resulted in leaf albino sectors 40 days after VIGS inoculation (Fig. 3a-e). The HrPDS was used as a positive control, whereas untransformed leaves were used as a negative control. Generally, the findings showed that different silenced genes caused various degrees of albinism in plants. Specifically, similar to the positive control, the $\mathrm{HrCAO}$-silenced plant showed the highest rates of albinism. While the $H r P O R$ silencing plant depicted the lowest one. Additionally, the expression levels of HrHEMA, HrPOR and HrCAO were significantly decreased after VIGS silencing treatment compared to the control. In particular, HrHEMA was decreased by $36.2 \%$, $H r P O R$ by $26.8 \%, H r C A O$ by $41 \%$ and $H r P D S$ by $52.5 \%$ (Fig. 3f). The ultrastructural observations results demonstrated that the cell permeability was changed, and many vesicles (autophagosome) appeared in the yellow part of leaves (Fig. 3g-j). The chloroplasts transformed from normal ellipses to roundness, thylakoids changed from flattened to swollen shape, and the inner membrane system was incomplete. Finally, mitochondria cristae were aggregated and well-developed after chlorophyll biosynthetic gene silencing.

\section{Expression patterns of HrHEMA, HrPOR and HrCAO in tobacco leaves under different light intensities}

In overexpressing tobacco plants, the expression level of HrHEMA, HrPOR and $H r C A O$ were significantly higher than those of WT plants. Different genes overexpressing tobacco plants exhibited different sensitivities to light. The highest expression level of HrHEMA and HrPOR was detected under $10,000 \mathrm{~lx}$ of illumination, while $\mathrm{HrCAO}$ showed the highest expression level under 6000 lx (Fig. 4a-c). Furthermore, it was noted that the total chlorophyll content in $\mathrm{HrPOR}$ - and $\mathrm{HrCAO}$-overexpressing in tobacco plants reached a peak under $6000 \mathrm{~lx}$ and 10,000 lx, respectively (Fig. 4d). After treating WT and transgenic tobacco plants with different light intensities (2000 lx, $6000 \mathrm{~lx}$ and 10,000 lx) for 40 days, it was noted that all tobacco leaves exhibited considerable changes (Fig. 4e). With the increase of light intensity, the leaf color gradually changed from light green to dark green. At $10000 \mathrm{~lx}$, the leaf color was relatively close to that under sunlight. Besides, palisade and spongy tissues appeared in $H r H E M A$ transgenic leaves, where light spots appeared on the surface of $\mathrm{HrCAO}$ transgenic tobacco leaves. After 70 days, substantial differences in plant growth were recorded under different light intensities, and specifically, the fastest growth rate was under 10 , $000 \mathrm{~lx}$, followed by $6000 \mathrm{~lx}$ and $2000 \mathrm{~lx}$. Moreover, the budding time of transgenic tobacco under 10,000 lx illumination was earlier compared to that of the control. Interestingly, the order of flowering time was as follows, the $\mathrm{HrCAO}$ transgenic tobacco was the earliest, then the HrPOR and HrHEMA transgenic tobacco, and finally the WT tobacco (Fig. 4f).

\section{Changes of chlorophyll biosynthetic precursors in HrHEMA-, HrPOR- and HrCAO-overexpressing tobacco seedlings}

Here, the enzyme 5-ALA, as the first universal precursor in the synthesis of chlorophyll, heme and other 

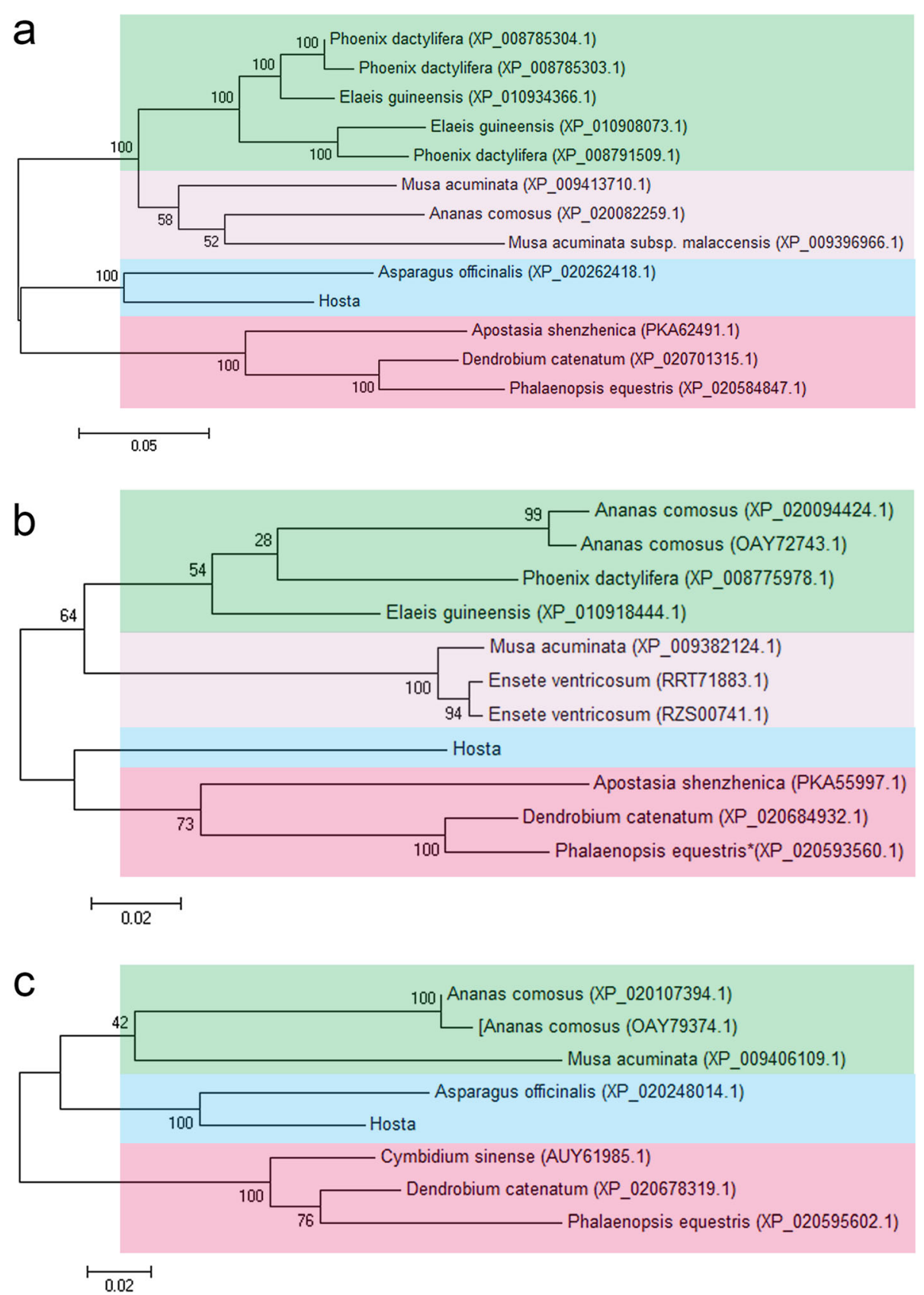

Fig. 1 Evolutionary relationship results of HrHEMA, HrPOR and HrCAO from different species. $\mathbf{a}$, $\mathbf{b}$, and $\mathbf{c}$ note the phylogenetic trees of HrHEMA, HrPOR and HrCAO from different species, respectively. Different colors represent different clustering groups

tetrapyrroles, revealed a relatively higher content in control than in the transgenic plants under $2000 \mathrm{~lx}$. Under $6000 \mathrm{~lx}$ illumination, HrHEMA- and HrCAO- overexpressing plants possessed a higher content of 5-ALA than those of HrPOR. On the contrary, HrPOR-overexpressing plants showed a higher 5-ALA than the HrHEMA and HrCAO transgenic plants under 10,000 lx (Fig. 5a). For porphobilinogen (PBG), no significant difference was noted under $2000 \mathrm{~lx}$ illumination. However,
PBG in HrPOR-overexpressing tobacco leaves elucidated the highest relative content under $6000 \mathrm{~lx}$, while that in HrHEMA transgenic tobacco leaves had the highest one under 10,000 lx (Fig. 5b). With the increase of light intensity, the uroporphyrinogen III content of WT, HrPOR - and HrCAO- overexpressing tobacco plants depicted an increasing trend. Additionally, the uroporphyrinogen III content of all the plants reached a peak under the light condition of $10,000 \mathrm{~lx}$. On the other 


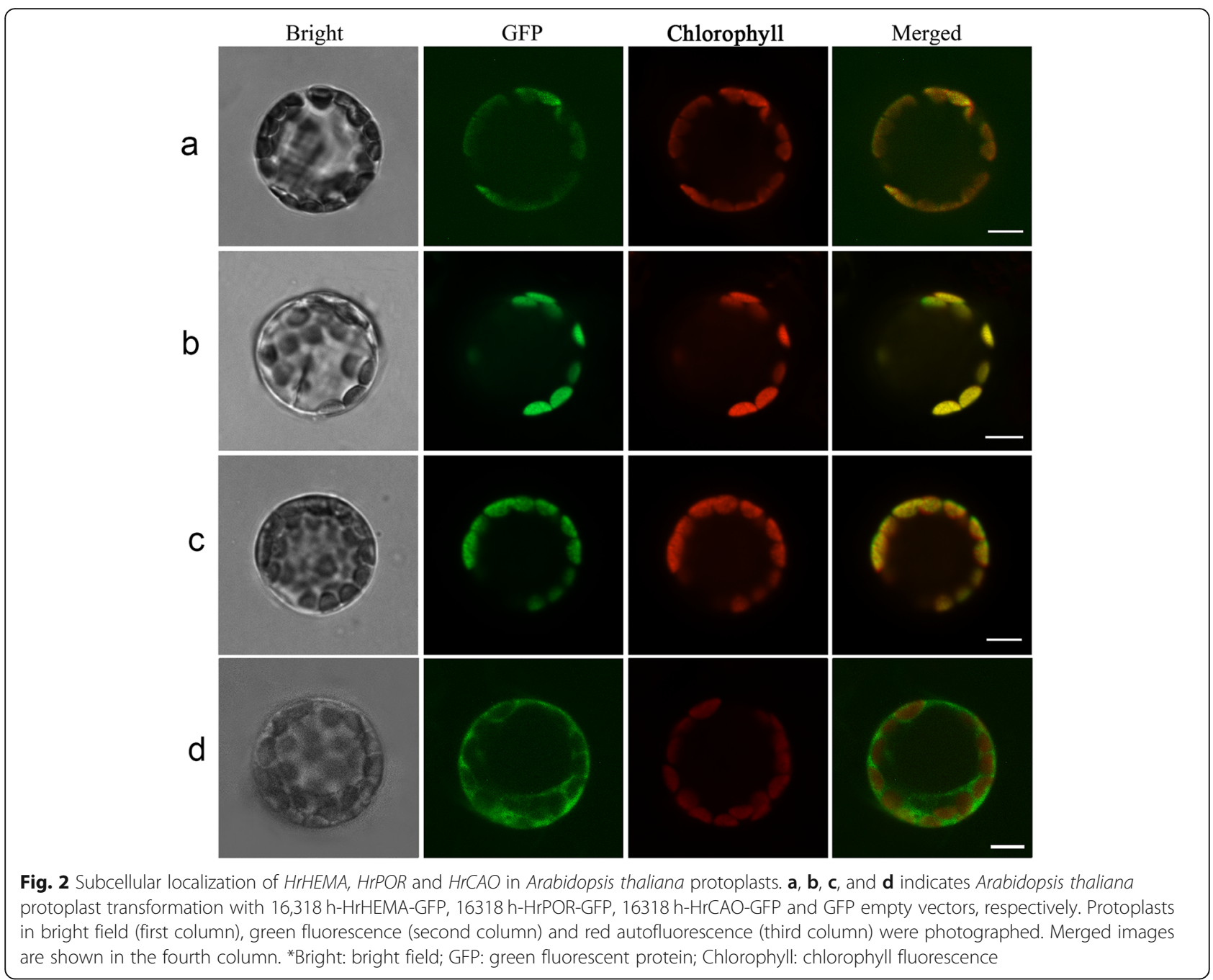

hand, the uroporphyrinogen III in HrHEMA overexpressing tobacco was first decreased and then increased. While in $H r P O R$ transgenic tobacco plants, uroporphyrinogen III was increased with the light intensity (Fig. 5c).

\section{Effect of overexpression of chlorophyll biosynthetic genes} on Chla, Chlb and cxc

The contents of Chla and Chlb increased gradually with light intensity and were higher in transgenic tobacco than those of WT under the same light condition. Furthermore, the Chla and Chlb contents of HrPOR- and $\mathrm{HrCAO}$ - overexpressing plants were increased considerably, especially under 10,000 lx illumination (Fig. 5d and e). The content of Cxc increased with the light intensity, but no significant difference was found among different groups under 2000 and $6000 \mathrm{~lx}$ illumination (Fig. 5f). However, under $10,000 \mathrm{~lx}$ illumination, the contents of Cxc in $H r P O R$ and $H r C A O$ transgenic tobacco plants were statistically higher than those in WT.
Effect of overexpression of chlorophyll biosynthetic genes on stress adjustment compounds

The contents of SOD, POD, MDA, Pro and CAT under different light conditions are summarized in Table 1. Under low light intensity, the SOD content in WT was higher than other groups. While under high light intensity, the SOD in $H r C A O$ and $H r P O R$ transgenic plants were relatively higher than others. POD illustrated a negative correlation with light intensity, while different gene overexpression had different effects. Especially in HrPOR transgenic plants, the POD content was significantly lower compared to other groups. For MDA, the contents in $\mathrm{HrCAO}$ and $\mathrm{HrPOR}$ transgenic plants and WT showed a negative correlation with light intensity, whereas those in HrHEMA-overexpressing plants displayed a positive correlation. Moreover, in general, the Pro contents in all the plants was negatively correlated with light intensity. Additionally, all the tobacco plants had significantly higher Pro contents under 2000 and $6000 \mathrm{~lx}$ illumination than that under 10,000 lx. Finally, 


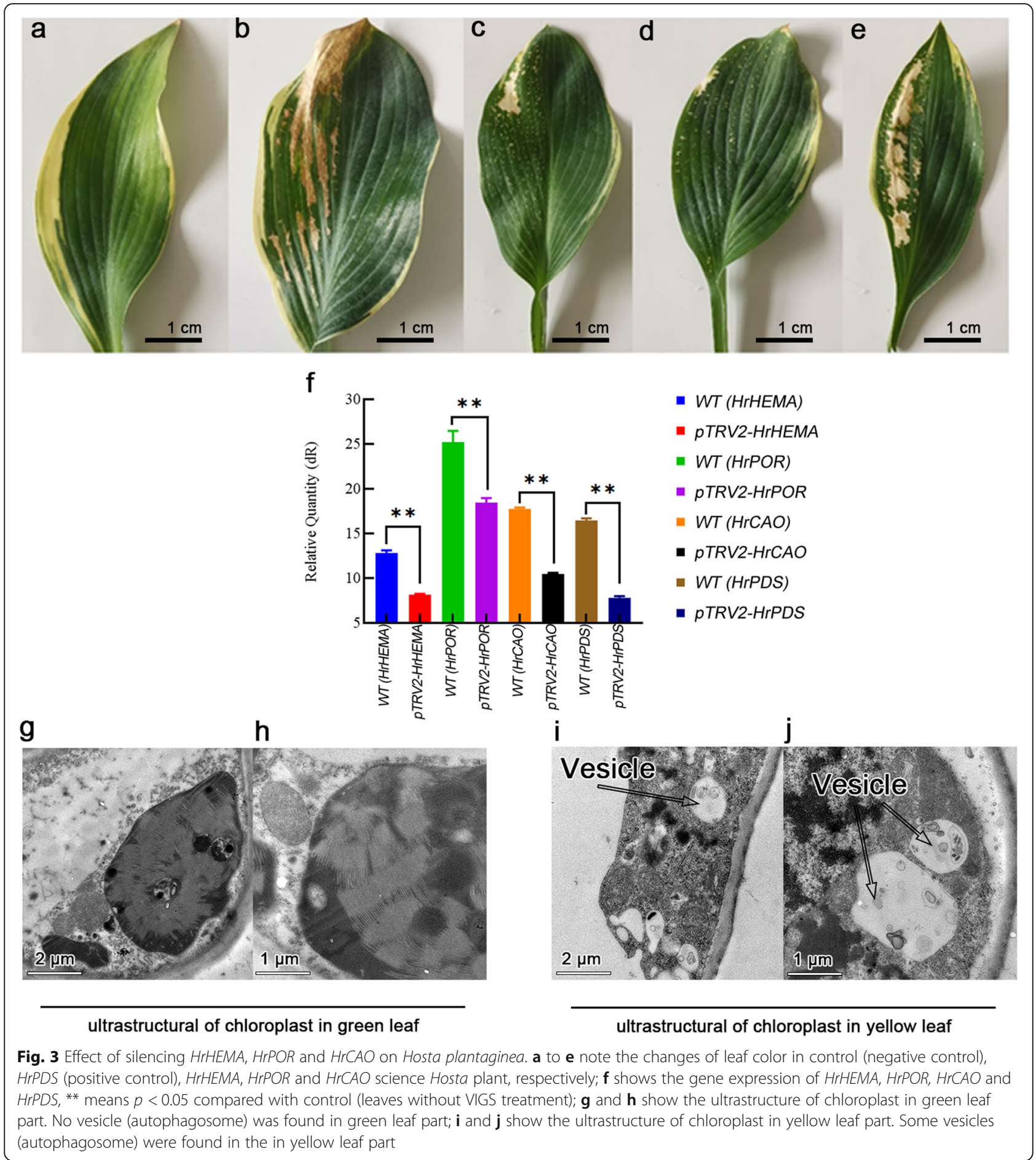

the CAT contents in all the transgenic tobacco plants were increased with light intensity, while the WT tobacco showed an opposite trend.

\section{Discussion}

The color change of plant leaves is a complex and sensitive process, controlled by a variety of genes, transcription factors and metabolic pathways. The color of plant leaves is attributed to the chlorophyll content, which is regulated by multiple genes, including $H E M A$, GSA, HEME, POR, CAP, CHLG and CHLM [27]. Previous studies have demonstrated a relationship between the expression levels of $H r H E M A, H r P O R$ and $H r C A O$ and leaf color in plants [28-30]. In this respect, we 


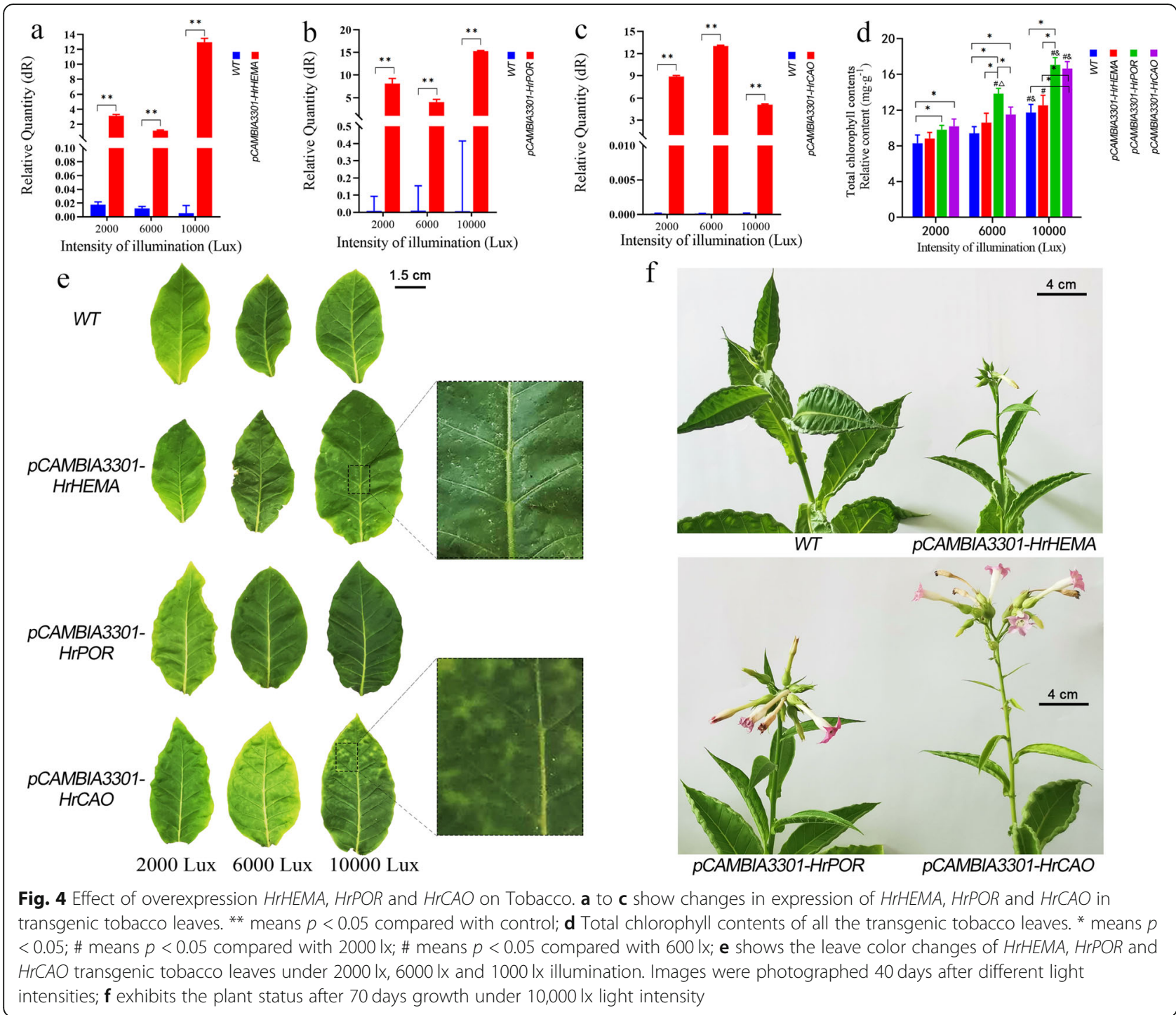

focused on the functions of $\operatorname{HrHEMA}, \operatorname{HrPOR}$ and $H r C A O$ and their relationship with light in Hosta.

Furthermore, HrHEMA, HrPOR and HrCAO genes, encoding the key enzyme for 5-ALA for chlorophyll synthesis, were isolated and characterized. As anticipated, the sanger sequence results of the three genes matched the reference gene sequence perfectly, indicating that the isolated genes were correct. Our phylogenetic tree outcomes revealed that Hosta had a closer relationship with Asparagus officinalis than other species, which is consistent with previous studies [31, 32]. Also, the phylogenetic trees agree well with the classification of the APG IV system [33]. The subcellular localization results revealed that all these three proteins were located in chloroplasts, which corroborates consistent with the results of previous studies [34-36].

After gene silencing, the expression levels of HrHEMA, $H r P O R$ and $H r C A O$ were decreased significantly.
Besides, the color of Hosta leaves changed significantly, which indicated that the expressions of HrHEMA, $H r P O R$ and $H r C A O$ in Hosta can directly affect the change of leaf color. However, silencing of different genes had different effects on the degree of leaf color changes. For example, the silencing of $\mathrm{HrCAO}$ mediated the formation of a large number of white spots in leaf. Chlb is one of the major light-harvesting pigments produced by land plants, green algae and several cyanobacterial species, which is synthesized from Chla by $C A O$ [37]. The chlorophyll cycle plays a crucial role in the processes of greening, acclimation to light intensity and senescence [38]. Studies have reported that the reduced expression level of $\mathrm{HrCAO}$ led to a decrease of Chlb, which might seriously interfere with the chlorophyll cycle and thus result in the leaf discoloration. On the other hand, the leaf color changed from light green to dark green in the $\mathrm{HrCAO}$-overexpressing tobacco plants, 


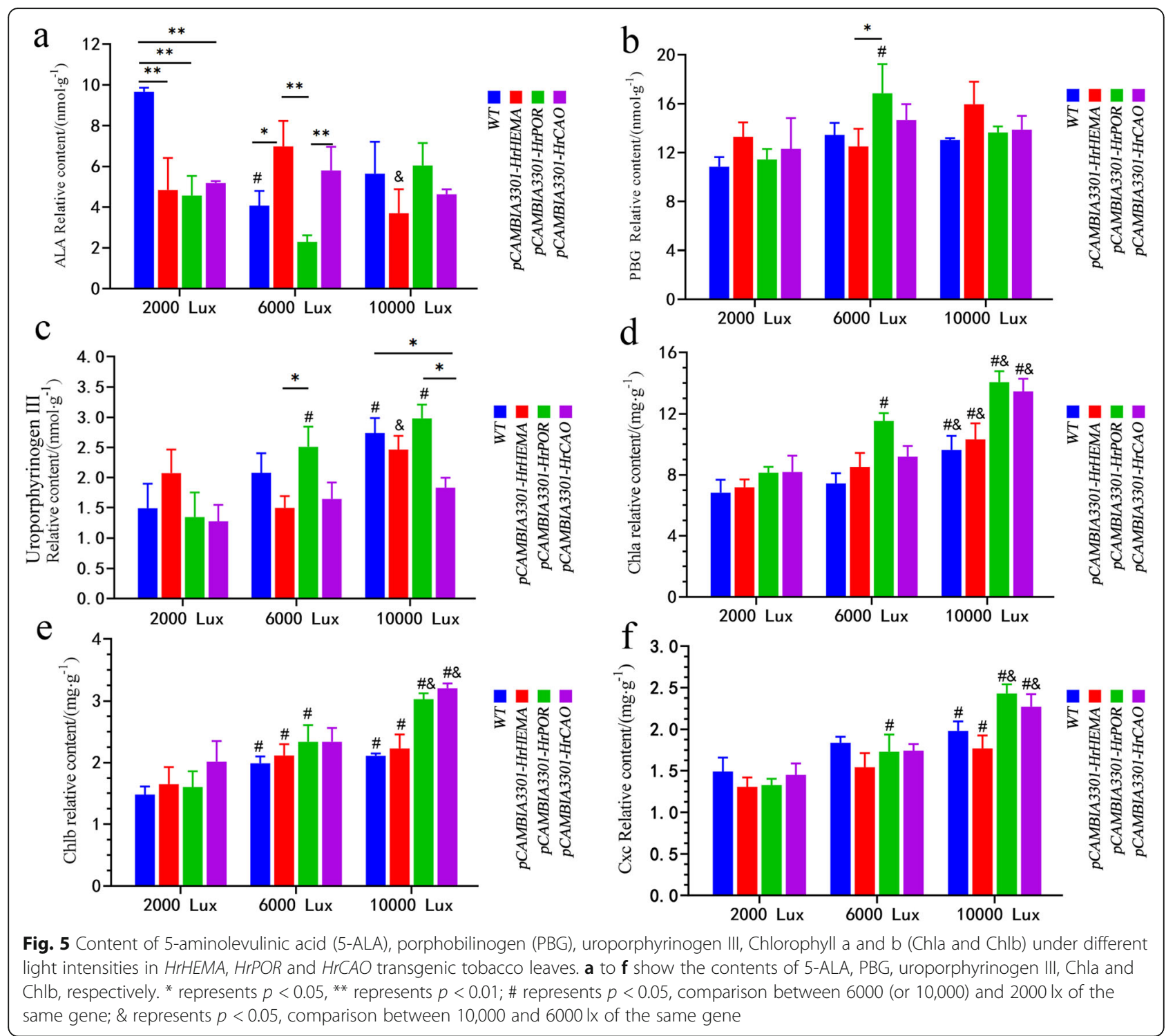

and mottled leaves appeared at $10000 \mathrm{~lx}$. In another study, the CAO-overexpressing tobacco plants have been reported to photosynthesize for a longer duration and retain larger biomass [39]. Overexpressing of a modified Arabidopsis CAO gene results in excessive accumulation of Chlb [40,41]. It is likely that the overexpression of $\mathrm{HrCAO}$ in tobacco mediates the accumulation of Chlb and retains larger biomass. Thus, the color gradually darkens. The rapid accumulation of Chla and Chlb and total chlorophyll content at $10000 \mathrm{~lx}$ also supported the fact that the accumulation of chlorophyll deepens the leaves color. The effect of $H r P O R$ gene silencing on leaf color was minimal of the three genes, and also the declining extent of expression level was the lowest. Of note, $\operatorname{HrPOR}$ silencing can cause white spots on the surface of leaves. On the contrary, its overexpression made the leaf color darker with the increase of light intensity.
The POR is a key regulatory enzyme in the chlorophyll synthesis pathway of all oxygen-producing photosynthetic organisms, participating in the enzymatic reduction of protochlorophyllide to chlorophyll by light. This is the first step in light-dependent chloroplast biosynthesis [42-44]. Multiple studies have noted that the light saturation point of tobacco seedlings is about $10,000 \mathrm{~lx}$ $\left(\sim 178.6 \mu \mathrm{mol} \cdot \mathrm{m}^{-2} \cdot \mathrm{s}^{-1}\right)$, while that for tobacco at the adult plant stage is about $30,000 \mathrm{~lx}\left(\sim 535.7 \mu \mathrm{mol} \cdot \mathrm{m}^{-2}\right.$. $\left.\mathrm{s}^{-1}\right)[45,46]$. According to our results, the PBG content under $6000 \mathrm{~lx}$ showed the maximum value, which indicated that the tobacco with $\mathrm{HrPOR}$ overexpression has faster photosynthetic rates while the peak light demand is lower. Elsewhere, in plant cells, PBG was converted to uroporphyrinogen III by uroporphyrinogen synthase (UROS) [47]. Here, the relative content of uroporphyrinogen III was increased rapidly under $6000 \mathrm{~lx}$ light, 
Table 1 Contents of SOD, POD, MDA, Pro and CAT

\begin{tabular}{|c|c|c|c|c|c|}
\hline & Illumination & Control & HrHEMA & HrPOR & HrCAO \\
\hline \multirow{3}{*}{$\begin{array}{l}\text { SOD } \\
\left(\mathrm{nmol} \cdot \mathrm{g}^{-1}\right)\end{array}$} & 2000 Lux & 457.95 & 410.17 & 394.26 & 331.70 \\
\hline & 6000 Lux & 322.87 & 317.56 & 372.31 & 343.21 \\
\hline & 10,000 Lux & 277.04 & 277.40 & 421.99 & 401.92 \\
\hline \multirow{3}{*}{$\begin{array}{l}\mathrm{POD} \\
\left(\mathrm{nmol} \cdot \mathrm{g}^{-1}\right)\end{array}$} & 2000 Lux & 4582.12 & 3870.28 & 1533.59 & 5521.09 \\
\hline & 6000 Lux & 3123.75 & 2880.60 & 832.71 & 2722.97 \\
\hline & 10,000 Lux & 2360.76 & 1241.45 & 330.64 & 588.15 \\
\hline \multirow{3}{*}{$\begin{array}{l}\mathrm{MDA} \\
\left(\mathrm{nmol} \cdot \mathrm{g}^{-1}\right)\end{array}$} & 2000 Lux & 32.31 & 23.67 & 38.67 & 23.37 \\
\hline & 6000 Lux & 23.50 & 26.30 & 28.66 & 42.95 \\
\hline & 10,000 Lux & 20.31 & 31.88 & 23.37 & 31.18 \\
\hline \multirow{3}{*}{$\begin{array}{l}\text { Pro } \\
\left(\mathrm{mg} \cdot \mathrm{g}^{-1}\right)\end{array}$} & 2000 Lux & 22.37 & 31.38 & 30.98 & 27.95 \\
\hline & 6000 Lux & 19.18 & 21.99 & 21.62 & 19.24 \\
\hline & 10,000 Lux & 12.42 & 12.30 & 11.49 & 10.59 \\
\hline \multirow{3}{*}{$\begin{array}{l}\text { CAT } \\
\left(\mathrm{nmol} \cdot \mathrm{g}^{-1}\right)\end{array}$} & 2000 Lux & 255.42 & 40.90 & 102.98 & 62.10 \\
\hline & 6000 Lux & 152.67 & 115.80 & 241.02 & 136.24 \\
\hline & 10,000 Lux & 27.63 & 267.23 & 325.05 & 275.84 \\
\hline
\end{tabular}

which was mediated by the increase of PBG. This further supported that HrPOR-overexpressing tobacco has a higher photosynthetic rate.

The contents of Chla and total chlorophyll in $\mathrm{HrPOR}$ transgenic tobacco were increased significantly under 6000 lx. Conversely, the contents of Chla, Chlb and total chlorophyll were increased significantly under 10,000 lx, which may be the main reason for the darkened green color. These findings are similar to the results of a previous study, where AtPORC-overexpression leads to a greener leaf phenotype in Arabidopsis [48]. Recently, several studies have reported that $P O R$ expression is induced by light, but shows different expression patterns in response to light [48-50]. In this study, HrPOR exhibited higher expression under $6000 \mathrm{~lx}$, but the accumulation of chlorophyll reached its peak at $10000 \mathrm{~lx}$, which indicated that moderate light intensity may be suitable for chlorophyll accumulation, and while excessive light intensity may induce opposite effects. The ALA is the precursor of Pchlide, which acts as a herbicide in the presence of light $[51,52]$. A study found that AhHEMA1-overexpressing tobacco can effectively yield in a prominent increase in ALA biosynthesis, with higher chlorophyll contents [53]. Herein, our results revealed that $H r H E M A$-overexpressing tobacco had lower 5-ALA contents under 2000 and 10,000 lx than WT, but showed higher content of 5-ALA under $6000 \mathrm{~lx}$. This signifies that the content of 5-ALA in WT maintained a high level under low light conditions, but after $\operatorname{HrHEMA}$ overexpression, the 5-ALA content was more sensitive to light and rapidly decomposed, even under low light conditions. In addition, the palisade and spongy tissues appeared in HrHEMA transgenic tobacco leaves, which was in line with the results reported by Schmied et al. [16], who recorded chlorosis and variegation in seedling growth under $160 \mu \mathrm{E}$ long sunshine conditions. The changes in chloroplast ultrastructure uncovered that the down-regulated HrHEMA, HrPOR and $\mathrm{HrCAO}$ significantly affected the chloroplast structure, which may be a major reason for the changes of the leaf color. The contents of Chla, Chlb and chlorophyll in transgenic plants were increased compared with the WT tobacco, which may enhance photosynthesis, improve light energy utilization rate, and promote the growth of tobacco plants to a certain extent. Furthermore, the transfer of HrHEMA, HrPOR and HrCAO can shorten the growth cycle [54], particularly for $\mathrm{HrCAO}$ transgenic tobacco. Our results correspond with previous findings [55]. Here, we summarized our results in Fig. 6.

Reactive oxygen species (ROS) play an integral role as signaling molecules in the regulation of numerous biological processes such as growth, development and responses to biotic and/or abiotic stimuli in plants [56, 57]. The balance of ROS in plant cells is important for plant development. The antioxidant defense system in the plant cell includes all enzymes such as SOD, POD and CAT [58].

The content of MDA, produced during peroxidation of membrane lipids, is often used as an indicator of oxidative damages [59]. Whereas that of Pro in a plant is a common response indicator to stress $[60,61]$. The relative contents of SOD, POD and CAT elucidated that the expressions of HrHEMA, HrPOR and $H r C A O$ can greatly affect their relative contents. However, here we noted that transgenic tobacco plants can enhance the activity SOD and CAT under strong illumination conditions, which can eliminate ROS produced in the intense photosynthesis process. Besides, transgenic tobacco plants depicted stronger photosynthesis ability, which may lead to an increase of MDA and Pro contents. Those findings were mainly regulated by heme, which might be used as a prosthetic group to participate in oxidative homeostasis [62]. Overall, $\mathrm{HrHEMA-,} \mathrm{HrPOR-}$ and $\mathrm{HrCAO}$-overexpressing tobacco can enhance the antioxidant capacity of plants to cope with stress under higher light intensity. Nevertheless, under lower light intensity, the antioxidant capacity of HrHEMA-, HrPOR- and HrCAO- overexpressing in tobacco declined.

\section{Conclusion}

In summary, $\operatorname{HrHEMA}, \mathrm{HrPOR}$ and $H r C A O$ silencing can cause leaf yellowing and chloroplast structure changes in Hosta. On note, leaves of Hosta with $\mathrm{HrCAO}$ silencing were the most affected, while the $H r P O R$ silencing plant was the least affected. The overexpression of these three genes in tobacco enhanced photosynthesis by accumulating chlorophyll content, but the influential 


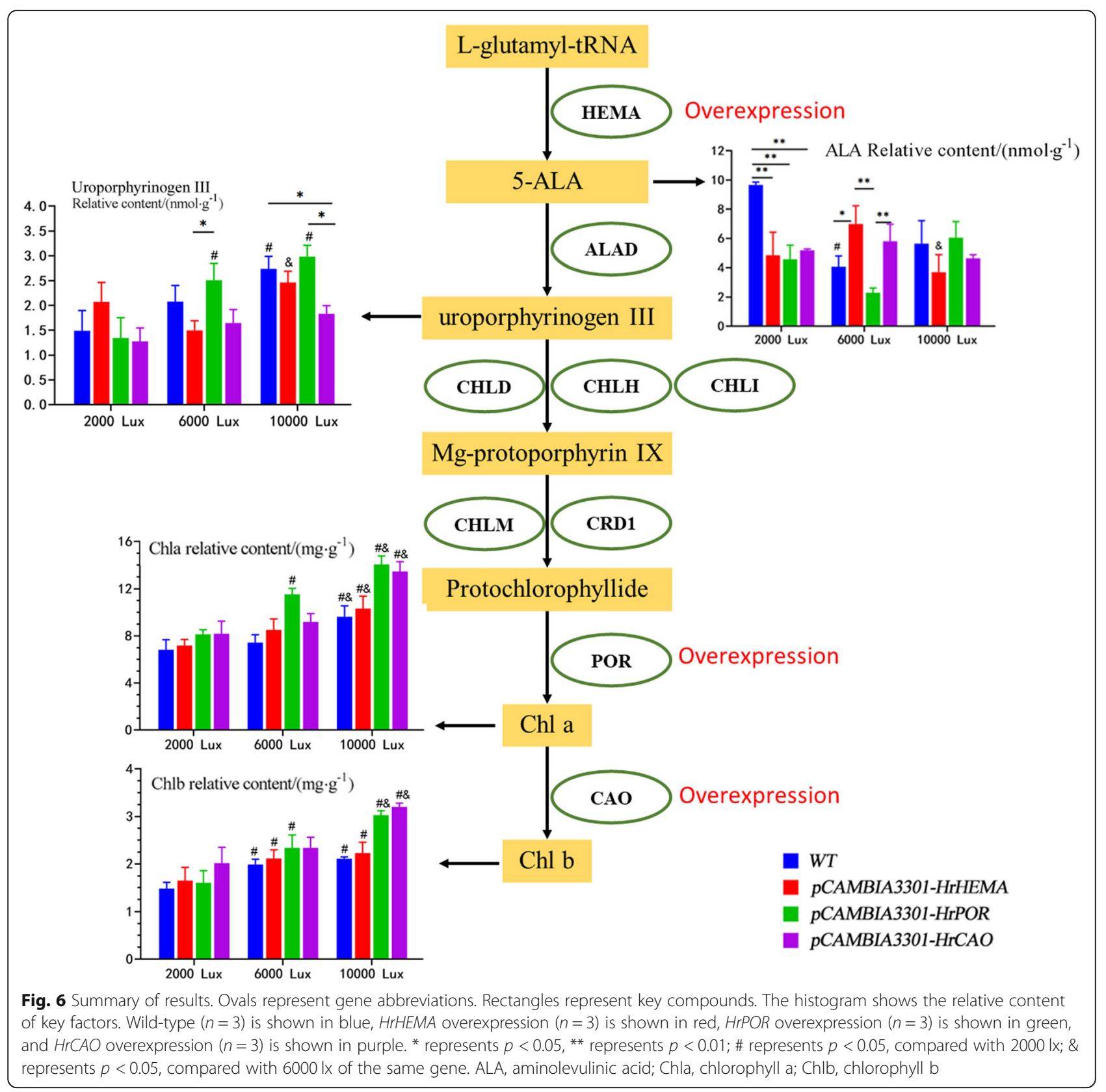

level varied under different light intensities. Furthermore, HrHEMA-, HrPOR- and HrCAO- overexpressing in tobacco can enhance the antioxidant capacity of plants to cope with stress under higher light intensity. However, under lower light intensity, the antioxidant capacity deteriorated in the HrHEMA-, HrPOR- and $\mathrm{HrCAO-overexpressing} \mathrm{tobaccos.}$

\section{Methods}

Plant materials, growth and treatments

Hosta (Lamarck cv. Regal Splendor), Arabidopsis (L. Heynh cv. Columbia) and tobacco (Nicotiana tabacum cv. NC89) plants were used in this study. Hosta were planted in the nurseries of Conservation and Exploitation of Wild Resources of Changbai Mountain, Jilin Agricultural University. Whilst Arabidopsis and tobacco were planted in an artificial climate chamber with illuminated conditions [4000 lx for Arabidopsis, $6000 \mathrm{~lx}$ for tobacco (tobaccos for illumination experiment were not included), 14 h/day] and mid-range humidity (40-60\%). Fresh plant leaves of Hosta were sampled and stored at $-80^{\circ} \mathrm{C}$ every 15 days. While those of Arabidopsis were used for protoplast preparation. For tobacco, seeds were disinfected with ethanol and sodium hypochlorite, and then sown on Murashige and Skoog (MS) media. After germination, seeds were transplanted in sterilized soil 
and grown in the artificial climate chamber for two weeks.

\section{Isolation of HrHEMA, HrPOR and HrCAO and sequence analysis}

Total RNA in Hosta leaves was extracted using a mini BEST Universal RNA Extraction Kit (TAKARA, Shiga, Japan). Then, a PrimeScript ${ }^{\mathrm{TM}} \mathrm{RT}$ reagent Kit 3.0 (TAKA RA, Shiga, Japan) was used for reverse-transcription PCR (RT-PCR). Afterward, gDNA Eraser was used to remove DNA from total RNA $(1 \mu \mathrm{g})$ with at $42{ }^{\circ} \mathrm{C}$ for 2 min, and then the transcription reaction mix was added and incubated at $37^{\circ} \mathrm{C}$ for $15 \mathrm{~min}$ and terminated at $85^{\circ} \mathrm{C}$ for $5 \mathrm{~s}$. The PCR conditions used for $\operatorname{HrHEMA}$, HrPOR and $H r C A O$ amplification with the paired primers (Table S2) were $94^{\circ} \mathrm{C}$ for $3 \mathrm{~min}$; 30 cycles at $98{ }^{\circ} \mathrm{C}$ for $10 \mathrm{~s}, 62{ }^{\circ} \mathrm{C}$ for $5 \mathrm{~s}, 72^{\circ} \mathrm{C}$ for $20 \mathrm{~s} ; 72^{\circ} \mathrm{C}$ for 10 min and held at $4{ }^{\circ} \mathrm{C}$. The $5^{\prime}$ - and $3^{\prime}$-fragments of these three genes were obtained from cDNA using the RACE Kit (TAKARA, Shiga, Japan). The obtained PCR fragments were subsequently cloned into the pEASY-Blunt Simple Cloning Vector (TransGen Biotech, Beijing, China). The recombinant plasmids were transformed into E. coli Trans1-T1, and white colonies were selected on LB plates containing $50.0 \mathrm{mg} / \mathrm{mL} \mathrm{Amp,} 500 \mathrm{mg} / \mathrm{mL}$ IPTG and $20 \mathrm{mg} / \mathrm{mL} \mathrm{X-gal.} \mathrm{To} \mathrm{characterize} \mathrm{the} \mathrm{isolated}$ genes, the sanger sequence was performed with the M13 primer (F: GAACACGGGGGACTCTTGAC; R: AATG TTTGAACGATCGGGGAAA) using an ABI $3730 \mathrm{xl}$ sequencer (ABI, CA, USA).

\section{Construction of phylogenetic trees}

The homologous sequences of $\operatorname{HrHEMA}, \operatorname{HrPOR}$ and $H r C A O$ were retrieved using Blast. The phylogenetic analysis of the ORF (Open Reading Frame) region for HrHEMA, $\mathrm{HrPOR}$ and $\mathrm{HrCAO}$ was executed, respectively, by comparing sequences and analyzing homology with homologous sequences. Briefly, the sequence multiple alignments were performed by the use of Clustal W with default parameters. Then the phylogenetic trees were constructed with the Maximum Likelihood (ML) algorithm using MEGA 6.0 (www.megasoftware.net/). Finally, the ML tree reliability was estimated using bootstrap analysis with 1000 replicates.

\section{Subcellular localization}

We constructed a vector expressing a GFP-tagged fusion protein for subcellular localization analysis of the HrHEMA, HrPOR and HrCAO protein. The cDNA containing the coding sequence of $\operatorname{HrHEMA}, \mathrm{HrPOR}$ and $\mathrm{HrCAO}$ were cloned into the $16,318 \mathrm{~h}$ GFP vector with a CaMV 35S promoter: green fluorescent protein (35S: GFP) cassette to construct fusion proteins following the previous report [63]. The recombinant vectors ( $p 35 S$ :
16318 h-HrHEMA-GFP, p35S:16318 h-HrPOR-GFP and p35S:16318h-HrCAO-GFP) were confirmed by sanger sequencing. The paired specific primers are listed in Table S2. The recombinant vectors were transformed into protoplasts using the polyethylene glycol (PEG)-mediated transformation method as described previously [64]. Fluorescence was examined under a Olympus FluoView FV1000 confocal laser scanning microscope (Olympus, Japan) $16 \mathrm{~h}$ after transformation.

\section{Plasmid construction and gene silencing in Hosta leaves}

For the gene silencing experiment, Hosta was used as the plant material. The full-length cDNA of $H r H E M A$, HrPOR and $H r C A O$ were inserted into VIGS vector pTRV2. Afterward, three VIGS expression vectors ( $p T R V 2-H r H E M A, p T R V 2-H r P O R$, and pTRV2-HrCAO), and positive control, $p T R V 2-P D S$ (Phytoene Desaturase), were inoculated into the Agrobacterium tumefaciens. The A. tumefaciens with the recombined vectors were injected into the leaf and stalk with Agro liquid culture using a 1-ml syringe. After injection, the seedlings were cultured in an incubator at $16{ }^{\circ} \mathrm{C}$ with a relative humidity of $60 \%$. After $24 \mathrm{~h}$, the seedlings were cultured at 22/ $18{ }^{\circ} \mathrm{C}$ and $16 \mathrm{~h}$ day $/ 8 \mathrm{~h}$ night. The qRT-PCR was performed 14days later to measure gene expression in order to verify the effect of gene silencing. Lastly, after 40 days, the plant leaves were observed and recorded for bleaching.

\section{Observation of leaf ultrastructure}

To observe the changes of the chloroplast in the different color parts of the Hosta leaf, the ultrastructure of a leaf was observed by transmission electron microscope (TEM, Hitachi, Tokyo, Japan). The center of the part to be detected was cut into small pieces (about $1 \mathrm{~mm}^{3}$ ) to ensure uniformity of samples. Then leaf tissues were fixed in $5 \%$ glutaraldehyde in $0.05 \mathrm{M}$ phosphate buffer ( $\mathrm{pH} 7.2$ ), post-fixed in $2 \%$ osmium tetroxide in the same buffer, dehydrated with a graded acetone series and propylene oxide, embedded in resin (analytically pure), and polymerized at $65^{\circ} \mathrm{C}$ for $24 \mathrm{~h}$. Samples were then observed by TEM at $100 \mathrm{kV}$.

\section{Plasmid construction and agrobacterium-mediated transformation of tobacco plants}

The full-length cDNAs of $\operatorname{HrHEMA}, \operatorname{HrPOR}$, and $H r C A O$ were cloned into the expression vector pCAMBIA3301 under the control of CaMV 35S promoter (http://www.cambia.org). The gusA acted as the reporter gene, which is only expressed in eukaryotic cells. The vectors of 35S:pCAMBIA3301-HrHEMA, 35S:pCAMBIA3301-HrPOR, 35S:pCAMBIA3301-HrCAO, and a control $p C A M B I A 3301$ were introduced into the $A$. tumefaciens strains using the freeze-thaw method. Leaf 
disk transformation was done based on the previous report [65]. After 2-3 weeks, the regenerated tobacco tissues were transferred to the medium for inducing roots. The qRT-PCR was employed for screening positive transgenic plants.

\section{Changes of transgenic tobacco under different light conditions}

Wild-type tobacco (WT, control) and transgenic tobacco plants at the seedling stage were treated with different light intensities including $2000 \mathrm{~lx}, 6000 \mathrm{~lx}$ and 10,000 lx. The changes in leaves were observed after 40 days while the plant growth was monitored after 70 days. In addition, the contents of 5-ALA and porphobilinogen (PBG) and relative contents of uroporphyrinogen III, chlorophyll a and b (Chla and Chlb), carotenoid (Cxc), superoxide dismutase (SOD), peroxidase (POD), malondialdehyde (MDA), proline (Pro) and catalase (CAT) under different light intensities were assessed as described elsewhere [66, 67].

\section{Quantitative real-time polymerase chain reaction (qRT- PCR) analysis}

Quantitative RT-PCR was implemented on an ABI 7500 Real-time PCR System using SYBR Real Master Mix (TAKARA, Shiga, Japan) with the following PCR thermal cycle conditions: denaturation at $95^{\circ} \mathrm{C}$ for $30 \mathrm{~s}, 40$ cycles at $95^{\circ} \mathrm{C}$ for $5 \mathrm{~s}, 58^{\circ} \mathrm{C}$ for $10 \mathrm{~s}$, and $68^{\circ} \mathrm{C}$ for $10 \mathrm{~s}$. Additionally, Hv-Actin and $\mathrm{Nt} \beta$-Actin were used as the reference genes in Hosta and tobacco, respectively (primers used are outlined in Table S2). Template-free, negative and single primer controls were established before the examination. The results are presented in three biological replicates (each with three technical replicates) for each sample, and the $2^{-\Delta \Delta}$ CT method was used for statistical analysis.

\section{Statistical analysis}

Statistical data analysis was executed following previous studies [68, 69]. In particular, GraphPad Prism 8 software was used for data statistical analysis. Data were analyzed using one-way ANOVA followed by multiple comparisons with the Tukey test. A value of $p<0.05$ was considered significant, while $p<0.01$ was considered highly significant.

\section{Supplementary Information}

The online version contains supplementary material available at https://doi. org/10.1186/s12870-020-02805-6.

Additional file 1: Table S1. Basic information of HrHEMA, HrPOR and HrCAO.

Additional file 2: Table S2. Primer sequences of gene cloning.
Additional file 3: Fig. S1. Alignment and evolutionary relationship results of HrHEMA from different species.

Additional file 4: Fig. S2. Alignment and evolutionary relationship finding of HrPOR from different species.

Additional file 5: Fig. S3. Alignment and evolutionary relationship results of $\mathrm{HrCAO}$ from different species.

\begin{abstract}
Abbreviations
PSI: photosystem I; PSII: photosystem II; GluTR: glutamyl-tRNA reductase; 5ALA: enzyme 5-aminolevulinic acid; GSA: Glu 1-semialdehyde; POR: protochlorophyllide oxidoreductase; CAO: Chla oxygenase; APG: Angiosperm Phylogeny Group; PBG: porphobilinogen; ROS: Reactive oxygen species; MS: Murashige and Skoog medium; RT-PCR: reversetranscription PCR; PDS: Phytoene Desaturase; Chla and Chlb: Chlorophyll a and b; Cxc: Carotenoid; SOD: Dismutase; POD: Peroxidase; MDA: Malondialdehyde; Pro: Proline; CAT: Catalase; qRT-PCR: Quantitative real-time polymerase chain reaction
\end{abstract}

\section{Acknowledgements \\ None.}

\section{Authors' contributions}

HZL designed the experiments. JZ, SL and HML carried out the experiments. JZ, CS and QY prepared the plant materials and analyzed the data. JZ, JC and $\mathrm{ZH}$ prepared the original manuscript. CS revised the structure of the original manuscript. JZ, CS, SL, HML, HZL revised the content of the manuscript. All authors approved the final manuscript.

\section{Funding}

This work was supported by Project of science and Technology Department of Jilin Province (20190301046NY) and National Achievements transformation project of the Ministry of science and technology (2014GB2B100007). The funding body had no role in study design, the collection, analysis, interpretation of data and manuscript writing.

\section{Availability of data and materials}

We uploaded the data to GenBank with the direct link and login number: https://www.ncbi.nlm.nih.gov/nuccore/MW217998, HrCAO.sqn HrHEMA MW217998; https://www.ncbi.nIm.nih.gov/nuccore/MW217999, HrCAO.sqn HrPOR MW217999; https://www.ncbi.nlm.nih.gov/nuccore/MW218000, HrCAO.sqn HrCAO MW218000. The data deposited in the GenBank is publicly available.

\section{Ethics approval and consent to participate}

Not applicable.

\section{Consent for publication}

Not applicable.

\section{Competing interests}

The authors have declared that no competing interests exist.

\section{Author details}

${ }^{1}$ College of Life sciences, Jilin Agricultural University, 2888 Xincheng Street, Changchun City 130000, People's Republic of China. ${ }^{2}$ Jilin Engineering Vocational College, Siping City, Jilin 136000, People's Republic of China.

Received: 10 May 2020 Accepted: 20 December 2020

Published online: 15 January 2021

\section{References}

1. Schmid WG. The genus Hosta. Portland: Timber Press; 2009.

2. Leifert C, Camotta H, Waites W. Effect of combinations of antibiotics on micropropagated Clematis, Delphinium, Hosta, Iris and Photinia. Plant Cell Tissue Organ Cult. 1992;29:153-60.

3. Liu JQ, Wang CF, Qiu M-H, Hu WX. Steroidal saponins from flowers of Hosta plantaginea and their antitumor activities. Chinese Traditional and Herbal Drugs. 2010;41:520-6. 
4. Yu F, Fu A, Aluru M, Park S, Xu Y, Liu H, Liu X, Foudree A, Nambogga M, Rodermel $\mathrm{S}$. Variegation mutants and mechanisms of chloroplast biogenesis. Plant Cell Environ. 2007;30:350-65.

5. Yuan M, Xu M-Y, Yuan S, Chen Y, Du J, Xu F, Zhang Z-W, Guo Z-C, Zhao Z-Y, Lin $\mathrm{H}-\mathrm{H}$. Light regulation to chlorophyll synthesis and plastid development of the chlorophyll-less Golden-leaf privet. J Integr Plant Biol. 2010;52:809-16.

6. Vaughn K. G. Wilson K, D. Stewart K: light-harvesting pigment-protein complex deficiency in Hosta (Liliaceae). Planta. 1978;143:275-8.

7. Fulgosi $H$, Jurić $S$, Lepeduš H, Hazler Pilepic K, Prebeg T, Ljubešić N. Thylakoid system disassembly during bleaching of aurea mutants of maple Acer negundo Hassk. Var. Odessanum. Croat Chem Acta. 2008;81:89-95.

8. Okabe K, H. Schmid G, Straub J: genetic characterization and high efficiency photosynthesis of an Aurea mutant of tobacco. Plant Physiol 1977, 60:150156.

9. Kawata $\mathrm{EE}$, Cheung AY. Molecular analysis of an aurea photosynthetic mutant (Su/Su) in tobacco: LHCP depletion leads to pleiotropic mutant phenotypes. EMBO J. 1991;9:4197-203.

10. Hou D-Y, Xu H, Du G-Y, Lin J-T, Duan M, Guo A-G. Proteome analysis of chloroplast proteins in stage albinism line of winter wheat (Triticum aestivum) FA85. BMB Rep. 2009:42:450-5.

11. Li Q, Huang J, Liu S, Li J, Yang X, Liu Y, Liu Z. Proteomic analysis of young leaves at three developmental stages in an albino tea cultivar. Proteome Sci. 2011:9:44.

12. Yang $Y$, Chen $X, X u B, L i$ Y, Ma Y, Wang G. Phenotype and transcriptome analysis reveals chloroplast development and pigment biosynthesis together influenced the leaf color formation in mutants of Anthurium andraeanum 'Sonate'. Front Plant Sci. 2015;6.

13. Li Y, Zhang Z, Wang P. Wang Sa, Ma L, Li L, Yang R, Ma Y, Wang Q: comprehensive transcriptome analysis discovers novel candidate genes related to leaf color in a Lagerstroemia indica yellow leaf mutant. Genes \& Genomics. 2015;37.

14. Fang $Y$, Zhao S, Zhang F, Zhao A, Zhang W, Zhang M, Liu L. The Arabidopsis glutamyl-tRNA reductase (GluTR) forms a ternary complex with FLU and GluTR-binding protein. Sci Rep. 2016;6:19756.

15. Madan Kumar A, Soll D. Antisense HEMA1 RNA expression inhibits Heme and chlorophyll biosynthesis in Arabidopsis. Plant Physiol. 2000;122:49-56.

16. Schmied J, Hedtke B, Grimm B. Overexpression of HEMA1 encoding glutamyl-tRNA reductase. J Plant Physiol. 2011;168:1372-9.

17. J Heyes $D$, Neil Hunter C: Making light work of enzyme catalysis: Protochlorophyllide oxidoreductase. Trends Biochem Sci 2005, 30:642-649.

18. Reinbothe C, El Bakkouri M, Buhr F, Muraki N, Nomata J, Kurisu G, Fujita Y, Reinbothe S. Chlorophyll biosynthesis: spotlight on protochlorophyllide reduction. Trends Plant Sci. 2010;15:614-24.

19. Scrutton N, Groot ML. J Heyes D: excited state dynamics and catalytic mechanism of the light-driven enzyme protochlorophyllide oxidoreductase. Physical chemistry chemical physics : PCCP. 2012;14:8818-24.

20. Gabruk M, Myśliwa-Kurdziel B. Light-dependent Protochlorophyllide oxidoreductase: phylogeny, regulation, and catalytic properties. Biochemistry. 2015;54.

21. Holtorf H, Reinbothe S, Reinbothe C, Bereza B, Apel K: Two Routes of Chlorophyllide Synthesis that are Differentially Regulated by Light in Barley (Hordeum vulgare L.). Proc Natl Acad Sci U S A 1995, 92:3254-3258.

22. Armstrong GA, Runge $S$, Frick $G$, Sperling $U$, Apel K. Identification of NADPH: protochlorophyllide oxidoreductases a and B: a branched pathway for lightdependent chlorophyll biosynthesis in Arabidopsis thaliana. Plant Physiol. 1995;108:1505-17.

23. Gabruk M, Stecka A, Strzałka W, Kruk J, Strzalka K, Beata M-K. Photoactive Protochlorophyllide-enzyme complexes reconstituted with PORA. PORB and PORC Proteins of A thaliana: Fluorescence and Catalytic Properties PLOS ONE. 2015;10:e0116990.

24. Zhou B, Peng D, Lin J, Huang X, Peng W, He R, Guo M, Tang D, Zhao X, Liu $X$. Heterologous expression of a gibberellin 2Oxidase gene from Arabidopsis thaliana enhanced the photosynthesis capacity in Brassica napus L. Journal of Plant Biology - J PLANT BIOL. 2011;54:23-32.

25. Dijkstra C, Adams E, Bhattacharya A. F page a, Anthony P, Kourmpetli S, B Power J, C Lowe K, Thomas S, Hedden P et al: over-expression of a GIBBERELLIN 2-OXIDASE gene from Phaseolus coccineus $L$. enhances gibberellin inactivation and induces dwarfism in Solanum species. Plant Cell Rep. 2008;27:463-70.

26. Pavla Novak DS. Research Progress on plant chlorophyll anabolism. Journal of Plant and Soil Science. 2019;1(1):10-5.
27. Eckhardt U, Grimm B, Hörtensteiner S. Recent advances in chlorophyll biosynthesis and breakdown in higher plants. Plant Mol Biol. 2004;56(1):114

28. Yangen F, Xiuxiu Z, Hanyue W, Yueyue T, Qinzeng X, Lixia Z: Effects of light intensity on metabolism of light-harvesting pigment and photosynthetic system in Camellia sinensis L. cultivar 'Huangjinya'. Environ Exp Bot 2019, 166 103796.

29. Li J, Wang Y, Chai J, Wang L, Wang C, Long W, Wang D, Wang Y, Zheng M, Peng $C$, et al. Green-revertible Chlorina 1 (grc1) is required for the biosynthesis of chlorophyll and the early development of chloroplasts in rice. Journal of Plant Biology. 2013;56(5):326-35.

30. Zhang K, Liu Z, Shan X, Li C, Tang X, Chi M, Feng H: Physiological properties and chlorophyll biosynthesis in a Pak-choi (Brassica rapa L. ssp. chinensis) yellow leaf mutant, pylm. Acta Physiologiae Plantarum 2016, 39(1):22.

31. McKain MR, Wickett N, Zhang Y, Ayyampalayam S, McCombie WR, Chase MW, Pires JC, de Pamphilis CW, Leebens-Mack J. Phylogenomic analysis of transcriptome data elucidates co-occurrence of a paleopolyploid event and the origin of bimodal karyotypes in Agavoideae (Asparagaceae). Am J Bot. 2012:99(2):397-406.

32. Lee S-R, Kim K, Lee B-Y, Lim CE. Complete chloroplast genomes of all six Hosta species occurring in Korea: molecular structures, comparative, and phylogenetic analyses. BMC Genomics. 2019;20(1):833.

33. Byng J, Chase M, Christenhusz M, Fay M, Judd W, Mabberley D, Sennikov A, Soltis $D$, Soltis $P$, Stevens $P$. An update of the angiosperm phylogeny group classification for the orders and families of flowering plants: APG IV. Bot J Linn Soc. 2016;181:1-20.

34. Tanaka R, Yoshida K, Nakayashiki T, Masuda T, Tsuji H, Inokuchi H, Tanaka A. Differential expression of two hemA mRNAs encoding glutamyl-tRNA reductase proteins in greening cucumber seedlings. Plant Physiol. 1996;110: $1223-30$.

35. Franck F, Sperling U, Frick G, Pochert B, van Cleve B, Apel K, A. Armstrong G: regulation of Etioplast pigment-protein complexes, inner membrane architecture, and Protochlorophyllide a chemical heterogeneity by lightdependent NADPH:Protochlorophyllide oxidoreductases a and B. Plant Physiol 2001, 124:1678-1696.

36. Eggink L, LoBrutto R, Brune D, Brusslan J, Yamasato A, Tanaka A, Hoober K. Synthesis of chlorophyll b: localization of chlorophyllide a oxygenase and discovery of a stable radical in the catalytic subunit. BMC Plant Biol. 2004;4: 5.

37. Kanematsu S, Sakuraba Y, Tanaka A, Tanaka R. Characterization of Arabidopsis mutants defective in the regulation of chlorophyllide a oxygenase. Photochem Photobiol Sci. 2008;7(10):1196-205.

38. Meguro M, Ito H, Takabayashi A, Tanaka R, Tanaka A. Identification of the 7hydroxymethyl chlorophyll a reductase of the chlorophyll cycle in Arabidopsis. Plant Cell. 2011;23(9):3442-53.

39. Biswal A, Pattanayak G, Pandey S, Leelavathi S, Siva Reddy V, Govindjee G, Tripathy B. Light intensity-dependent modulation of chlorophyll b biosynthesis and photosynthesis by overexpression of Chlorophyllide a oxygenase in tobacco. Plant Physiol. 2012;159:433-49.

40. Yamasato A, Nagata N, Tanaka R, Tanaka A. The N-terminal domain of Chlorophyllide a oxygenase confers protein instability in response to chlorophyll b accumulation in Arabidopsis. Plant Cell. 2005;17:1585-97.

41. Sakuraba Y, Balazadeh S, Tanaka R, Mueller-Roeber B, Tanaka A. Overproduction of $\mathrm{Chl} b$ retards senescence through transcriptional reprogramming in Arabidopsis. Plant \& cell physiology. 2012;53:505-17.

42. Armstrong GA, Runge S, Frick G, Sperling U, Apel K. Identification of NADPH: Protochlorophyllide oxidoreductases a and B: a branched pathway for lightdependent chlorophyll biosynthesis in Arabidopsis thaliana. Plant Physiol. 1995;108(4):1505-17.

43. Czarnecki O, Gläßer C, Chen J-G, Mayer KFX, Grimm B. Evidence for a contribution of ALA synthesis to plastid-to-nucleus signaling. Front Plant Sci. 2012;3:236-6.

44. Jung K-H, Lee J, Dardick C, Seo Y-S, Cao P, Canlas P, Phetsom J, Xu X, Ouyang $\mathrm{S}$, An $\mathrm{K}$, et al. Identification and functional analysis of lightresponsive unique genes and gene family members in rice. PLOS Genet. 2008:4(8):e1000164-4.

45. Liu XLZ: A Study on the Growth Patterns and Photosynthetic Characteristics of Flue-cured Tobacco during Seedling. Acta Tabacaria Sinica 1993, 1(4).

46. Zhang LJSCXDXXWLR: Effect of different light intensity on photosynthesis of tobacco. 6 2000(4):17-21. 
47. Fujiwara T, Harigae H. Molecular pathophysiology and genetic mutations in congenital sideroblastic anemia. Free Radic Biol Med. 2019;133:179-85.

48. Pattanayak G, Tripathy B. Overexpression of Protochlorophyllide oxidoreductase $\mathrm{C}$ regulates oxidative stress in Arabidopsis. PLoS One. 2011; 6:e26532.

49. Su Q, Frick G, Armstrong GA, Apel K. POR C of Arabidopsis thaliana: a third light- and NADPH-dependent protochlorophyllide oxidoreductase that is differentially regulated by light. Plant Mol Biol. 2002;47:805-13.

50. Masuda T, Fusada N, Oosawa N. Takamatsu Ki, Yamamoto Y, Ohto M, Nakamura K, Goto K, Shibata D, Shirano Y et al: functional analysis of isoforms of NADPH: protochlorophyllide oxidoreductase (POR), PORB and PORC, in Arabidopsis thaliana. Plant \& cell physiology. 2003;44:963-74.

51. Rebeiz C, Mayasich J, Tripathy B. C. Rebeiz C, C. Friedmann H: photodynamic herbicides. Recent developments and molecular basis of selectivity. Critical Reviews in Plant Sciences - CRIT REV PLANT SCI. 1988;6:385-436.

52. Tripathy B, Chakraborty N: 5-Aminolevulinic Acid Induced Photodynamic Damage of the Photosynthetic Electron Transport Chain of Cucumber (Cucumis sativus L.) Cotyledons. Plant Physiol 1991, 96:761-767.

53. Yang S, Zhao L, Yan J, Zhang J, Guo F, Geng Y, Wang Q, Yang F, Wan S, L $X-G$. Peanut genes encoding tetrapyrrole biosynthetic enzymes, AhHEMA1 and AhFC1, alleviating the salt stress in transgenic tobacco. Plant Physiol Biochem. 2019;137.

54. Pattanayak GK, Biswal AK, Reddy VS, Tripathy BC. Light-dependent regulation of chlorophyll b biosynthesis in chlorophyllide a oxygenase overexpressing tobacco plants. Biochem Biophys Res Commun. 2005;326(2): 466-71

55. Zhang WZC-pLX-gZY: Construction of transgenic tobacco containing Arabidopsis thaliana CAO gene and analysis of its low light tolerance. Journal of Southern Agriculture 2015, 46(6):951-957.

56. Swanson S, Gilroy S. ROS in plant development. Physiol Plant. 2009;138:38492.

57. Baxter A, Mittler R, Suzuki N. ROS as key players in plant stress signaling. J Exp Bot. 2013;65.

58. Gunes A, Inal A, Guneri E, Coban S, Sahin O. Silicon increases boron tolerance and reduces oxidative damage of wheat grown in soil with excess boron. Biol Plant. 2007;51:571-4

59. Mittler R. Oxidative stress, antioxidants and stress tolerance. Trends Plant Sci. 2002;7:405-10

60. Karabal E, Yücel M, Oktem H. Antioxidant responses of tolerant and sensitive barley cultivars to boron toxicity. Plant Sci. 2003;164:925-33.

61. Jimenez J, Becerra-Flora A, Hernández-Lucero E, Rodríguez-Kessler M, Acosta-Gallegos J, G. Ramírez-Pimentel J: proline accumulation in two bean cultivars under salt stress and the effect of polyamines and ornithine. Biol Plant 2006, 50:763-766.

62. A Khan A, G Quigley J: Control of intracellular heme levels: Heme transporters and Heme oxygenases. Biochim Biophys Acta 2011, 1813:668682.

63. Huang $X$, Yan $H$, Zhai $L$, Yi Y. GLABROUS1 from Rosa roxburghii Tratt regulates trichome formation by interacting with the GL3/EGL3 protein. Gene. 2019;692:60-7.

64. Bart R, Chern M, Park C-J, Bartley L, Ronald PC. A novel system for gene silencing using siRNAs in rice leaf and stem-derived protoplasts. Plant Methods. 2006;2:13-3.

65. Curtis IS, Davey MR, Power JB. Leaf disk transformation. Methods Mol Biol. 1995;44:59-70

66. Jain M, Panwar M, Gadre R. Influence of selenium supplementation on $\delta$ Aminolevulinic acid formation in greening maize leaf segments. Research Journal of Phytochemistry. 2017;11:111-7.

67. Barcelos JPQ, Reis HPG, Godoy CV, Gratão PL, Furlani Junior E, Putti FF, Campos M, Reis AR: Impact of foliar nickel application on urease activity, antioxidant metabolism and control of powdery mildew (Microsphaera diffusa) in soybean plants. 2018, 67(7):1502-1513.

68. Lu Z, Deng Y, Van Nostrand JD, He Z, Voordeckers J, Zhou A, Lee YJ, Mason OU, Dubinsky EA, Chavarria KL, et al. Microbial gene functions enriched in the Deepwater horizon deep-sea oil plume. ISME J. 2012;6(2):451-60.

69. Yang Y, Wu L, Lin Q, Yuan M, Xu D, Yu H, Hu Y, Duan J, Li X, He Z, et al. Responses of the functional structure of soil microbial community to livestock grazing in the Tibetan alpine grassland. Glob Chang Biol. 2013; 19(2):637-48.

\section{Publisher's Note}

Springer Nature remains neutral with regard to jurisdictional claims in published maps and institutional affiliations.

\section{Ready to submit your research? Choose BMC and benefit from:}

- fast, convenient online submission

- thorough peer review by experienced researchers in your field

- rapid publication on acceptance

- support for research data, including large and complex data types

- gold Open Access which fosters wider collaboration and increased citations

- maximum visibility for your research: over $100 \mathrm{M}$ website views per year

At BMC, research is always in progress.

Learn more biomedcentral.com/submissions 